\title{
Photosynthetic activity of red and green leaf sectors in Coleus blumei plants as sensed by chlorophyll fluorescence
}

\author{
K.H. LIN*, M.Y. HUANG ${ }^{*+}$, J.H. WENG ${ }^{* *+,}$, and S.C. KAO ${ }^{* *}$ \\ Department of Horticulture and Biotechnology, Chinese Culture University, Taipei 11114, Taiwan* \\ Department of Life Sciences, National Chung-Hsing University, 40227 Taichung, Taiwan ${ }^{* *}$
}

\begin{abstract}
The changes and responses in the chlorophyll (Chl) fluorescence (ChlF) components were studied on the red and green parts of leaves in three Coleus blumei varieties under different light intensities. Chl $a$, carotenoids (Car), and SPAD were linearly, positively, and significantly correlated with total Chl $[$ i.e., Chl $(a+b)]$ of red and green leaves. Significant differences in Chl and Car contents were noted between differentially pigmented sectors of the leaf, but no anthocyanin content was found in the green parts compared to red leaves. Values of minimal and maximal fluorescence yields in darkand light-adapted states in both red and green leaves were all positively and significantly correlated with $\mathrm{Chl}$ contents under dark conditions and all PPFD treatments for 20 min. Assessing the ChlF parameters under PPFD variations is an important tool for finding improved photosynthetic productivity of plants.
\end{abstract}

Additional key words: light intensity; light response; photosynthetic efficiency; photosynthetic photon flux density.

\section{Introduction}

Chloroplasts are a major target of many environmental stress factors. Plants respond to sudden and sustained fluctuations in light intensities partly via their chloroplast molecularredox-signaling transduction mechanisms, which initiate marked modulations in chloroplast components, ultimately leading to acclimation of the photosynthetic apparatus (Anderson et al. 1997). Light intensity is one of the major factors that affect the growth, leaf form, floral morphology, and biochemical characteristics of plants, and it is also associated with the photosynthetic efficiency of plants (Montgomery and Givnish 2008). At high light intensities, photosynthetic carbon fixation increases, but the excess light is a stressor and therefore causes depression of the photosynthetic efficiency (Powles 1984). The study of photosynthesis-irradiance relation-ships is a basic aspect of plant ecophysiological research and is important for managing rare species; photosynthetic light-response curves are used to assess the ability to capture light and understand optimal habitat light conditions of plants (Aleric and Kirkman 2005). Insufficient light can limit photosynthesis, which causes reductions in net carbon gains and plant growth. Contrary, under high irradiance, during the light reaction, plants can absorb more photons than can be used by carbon fixation reactions, e.g., by leaves in the upper canopy layer exposed to the sun and also by shade leaves exposed to sunflecks. The excessive absorbed energy can lead to reductions in the efficiency of photosystems, especially PSII (Adams et al. 2004).

High contents of pigments in the leaves can be attributed to a wide occurrence of those plants under high light conditions (de la Rosa-Manzano et al. 2015). Elevated Chl contents in red-leafed plants were associated with lower Chl $a / b$ ratios similar to shade-adapted plants (Liakopoulos and Spanorigas 2012). Variations in the Chl $a / b$ ratio occur due to differences in PSI/PSII ratios as well as the size and composition of light-harvesting complexes associated with each photosystem and containing different amounts of Chl $b$ (Borek et al. 2016). Stress decreases the ability of photosynthetic systems to utilize incident photons, thus leading to photoinhibition, and reduced quantum yields of photochemistry and chlorophyll fluorescence (ChlF). Photoinhibition causes inhibition of PSII, while also increases thermal deexcitation of excited Chl (DemmigAdams et al. 1996). Electrons transferred from PSII to PSI are used by downstream electron sink pathways, including photosynthetic carbon fixation and photorespiration. When carbon fixation becomes saturated, photosynthesis is unable to use all of the energy absorbed by plants under high light (Dewir et al. 2015). Plants adapt photosynthesis to a certain degree in response to the prevailing environment, and the sensitivity of photosynthesis to stress varies among plant species and cultivars. ChlF,

$\overline{\text { Received }} 27$ August 2018, accepted 10 December 2018.

${ }^{+}$Corresponding author; e-mail: hmy6@ulive.pccu.edu.tw (M.Y. Huang), jhweng@mail.cmu.edu.tw (J.H. Weng)

Abbreviations: Ant - anthocyanins; Car - carotenoids; Chl - chlorophyll; ChlF - chlorophyll fluorescence; $\mathrm{F}_{0}$ - minimum fluorescence yield in a dark-adapted state; $F_{0}{ }^{\prime}$ - minimum fluorescence yield in a light-adapted state; $F_{m}$ - maximum fluorescence yield in a darkadapted state; $F_{m}{ }^{\prime}-$ maximum fluorescence yield in a light-adapted state; $F_{v} / F_{m}$ - maximum photochemical quantum yield; NPQ nonphotochemical quenching; SPAD - soil-plant analysis development. 
a noninvasive technique, offers highly accurate measurements that illustrate the photosynthetic performance of plants, and is often used to investigate a plant's response to various abiotic and biotic stresses in controlled environments and in the field (Nedbal et al. 2000, Pineda et al. 2008, Rahbarian et al. 2011, Takayama et al. 2011, Dos Anjos et al. 2012, Wilson and Jacobs 2012, Huang et al. 2013, Muniz et al. 2014). Measuring ChlF is a simple, rapid, and accurate method that can be performed with portable equipment, during which no materials are consumed (Molina-Bravo et al. 2011). However, functioning of the photosynthetic apparatus has not been examined yet by ChlF in Coleus blumei plants under different light intensities. Understanding the photosynthetic characteristics of $C$. blumei would benefit field cultivation management.

Coleus blumei, a member of the Lamiaceae, is an ornamental garden plant that has become popular due to a large number of cultivars with highly decorative and variegated leaves. The colors of Coleus foliage range from green, yellow, orange, and brown through purple to red and pink (Osman 2013). Coleus leaf colors depend on the presence of pigments including Chls, anthocyanins (Ant), carotenoids (Car), flavonoids, and betalains (Tanaka et al. 2008). Coleus plants are sensitive to environmental changes and may exhibit changes in leaf structure and physiological conditions of their leaves (Padri and Umponstira 2017). Furthermore, this species is also sensitive to changes in light intensity and has a rapid phenotypic response to it, but there is limited information available regarding the photosynthetic activity of these plants. The hypothesis of this research was that some of the ChlF components might exhibit distinguishable differences between green and red parts of leaves in plants under different light intensities since pigment composition of the leaves is different. The aim of this study was to determine the actual state of the photosynthetic apparatus in differentially pigmented leaves of multicolored leaves of three Coleus cultivars. The mechanisms of the capture, transfer, and dissipation of excitation energy were detected by ChlF measurements within an individual leaf with green and red coloration in response to various light intensities. ChlF can be considered a selection index to examine the growth of Coleus plants under broad ranges of light intensity. Relationships of $\mathrm{ChlF}$ indices with $\mathrm{Chl}$ and other pigments can be used for ecophysiological research in C. blumei plants. Precise management of the photosynthetic capacity in response to PPFD can potentially be used to maximize the efficiency of the growth and development of Coleus plants grown in controlled environments for economic benefits.

\section{Materials and methods}

Plant material and culture practice: Plants of three C. blumei cultivars, 'Blumei Benth' (BB), 'Wizard Rose' (WR), and 'Solenostemon Scutellaroides' (SS) (Fig. 1S, supplement), were purchased from local flower shops in Taipei (Taiwan), and were used in all experiments undertaken in this study. BB plants have medium-large, yellowish-green leaves with red sectors near the main veins. The edges of the foliage are surrounded by arrowshaped tips. WR leaves have large and wide red centers surrounded by narrow outer margins of light-green and white. SS plants have large leaves with red centers, while bright-green fragments form a very wide and large outline located mainly at the base of the leaf borders. Plants $(16-20 \mathrm{~cm}$ tall) were transplanted into $20-\mathrm{cm}$ plastic pots $(1,444 \mathrm{~mL})$ containing commercial potting soil with a $1: 1: 1(\mathrm{v} / \mathrm{v} / \mathrm{v})$ mixture of sand, peat moss, and perlite, and were placed in a greenhouse. Plants were evenly spaced to promote similar growth rates and sizes. Plants were watered daily, and optimal amounts of a liquid fertilizer solution of $0.1 \% \mathrm{NH}_{4} \mathrm{NO}_{3}$ and $\mathrm{K}_{2} \mathrm{HPO}_{4}(50 \mathrm{~mL})$ were applied weekly. Plants were grown for 1 month, and those with a uniform size of $30-40 \mathrm{~cm}$ in height were selected and randomly separated into three groups for subsequent experiments. During the period of plant growth, average day/night temperatures were $30 / 22^{\circ} \mathrm{C}$, and the average day length was $14 \mathrm{~h}$ under a natural light intensity of 500-700 $\mu$ mol(photon) $\mathrm{m}^{-2} \mathrm{~s}^{-1}$ in a greenhouse, and the relative humidity was approximately $60 \%$. All plants were free from any disease or nutrient shortage.

Determination of Chl, Car, and Ant contents: Contents of Chls and Car in red and green sectors of leaves were determined using methods described by Lichtenthaler et al. (1987). In brief, leaf discs were excised using a standard hole punch, immediately sealed in prelabeled aluminum envelopes, and placed in liquid nitrogen. Tissues were stored at $-80^{\circ} \mathrm{C}$ until analysis, and then extracted in a solvent mixture of acetone, methanol, and water (80:15:5, $\mathrm{v} / \mathrm{v} / \mathrm{v})$ at $4^{\circ} \mathrm{C}$ overnight. The supernatant was obtained by centrifuging the mixture at $13,000 \times g$ for $10 \mathrm{~min}$. Supernatants were assayed for the absorbance of Chl $a$ and $\mathrm{Chl} b$ in acetone at 663 and $647 \mathrm{~nm}$, respectively, with a U-2000 type spectrophotometer (Hitachi, Tokyo, Japan). $\mathrm{Chl} a, \mathrm{Chl} b$ and Car concentrations were calculated using the following equations:

$$
\begin{aligned}
\text { Chl } a= & 0.01373 \times \mathrm{OD}_{663}-0.000897 \times \mathrm{OD}_{537} \\
& -0.003046 \times \mathrm{OD}_{647}, \\
\mathrm{Chl} b= & 0.02405 \times \mathrm{OD}_{647}-0.004359 \times \mathrm{OD}_{537} \\
& -0.005507 \times \mathrm{OD}_{663}, \\
\mathrm{Car}= & {\left[\mathrm{OD}_{470}-(17.1 \times(\mathrm{Chl} a+\mathrm{Chl} b)-9.479 \times \mathrm{Ant})\right] / } \\
& 119.26 .
\end{aligned}
$$

Ant contents of the extracts were measured based on the protocol of Mancinelli and Rabino (1984). Red and green sectors of leaf discs were immersed in boiling methanol/ $\mathrm{H}_{2} \mathrm{O} / \mathrm{HCl}(90: 10: 1, \mathrm{v} / \mathrm{v} / \mathrm{v})$ for $10 \mathrm{~min}$ and incubated for $1 \mathrm{~h}$ at room temperature. The mixture was then centrifuged at $3,000 \mathrm{rpm}$ and $4{ }^{\circ} \mathrm{C}$ for $5 \mathrm{~min}$ to obtain the supernatant, followed by measuring the absorbances at $530\left(\mathrm{~A}_{530}\right)$ and $657 \mathrm{~nm}\left(\mathrm{~A}_{657}\right)$ by a spectrophotometer. The following equation was used: $\mathrm{Ant}=\mathrm{A}_{530}-\left(0.25 \times \mathrm{A}_{657}\right)$.

In addition, total $\mathrm{Chl}$ contents of red and green parts of leaves were determined using a nondestructive Chl estimation by SPAD analyzer (SPAD-502, Konica Minolta, Tokyo, Japan). Measurements were collected from 16 mature, healthy, and fully expanded leaves from the middle to upper 
portion of each plant and averaged. SPAD values were determined using dual wavelength optical absorbances at 650 and $940 \mathrm{~nm}$ (Bonneville and Fyles 2006). Leaf veins were avoided during the measurement.

Leaf spectral measurement: After SPAD measurements, reflectance was measured on red and green sectors of leaves in a plant with different total Chl [i.e., Chl $(a+b)]$ contents using a bifurcated fiber optic cable and a leafclip of a spectrometer (CI-700, CID Inc., Vancouver, WA, USA) according to Xue et al. (2014). Tested leaves were irradiated from one side with a tungsten halogen lamp in the spectrometer using the bifurcated fiber cable. The experimental setup provided a spectral range of 400$700 \mathrm{~nm}$. Transmittance was measured according to the method of Konoplyova et al. (2008). The absorbance (A) was calculated as: $\mathrm{A}=1-$ (Reflectance + Transmittance).

Determination of ChIF variables: In order to understand better the ecophysiology of $C$. blumei plants, the relationship of the photosynthetic efficiency with $\mathrm{Chl}(a+b)$ content was analyzed by determining the ChlF index. The potted plants were moved to a dark room overnight, and the middle portions of both red and green leaves of a plant were used for the measurements. The overnight dark-adapted plants were exposed to light stepwise from low to high levels of PPFD (i.e., 200, 400, 800; 1,200; and $2,000 \mu \mathrm{mol} \mathrm{m} \mathrm{m}^{-2} \mathrm{~s}^{-1}$ ), by a slide projector with a tungsten halogen lamp for $20 \mathrm{~min}$. After illumination, leaves were adapted in the dark for $20 \mathrm{~min}$. The ChlF parameters of dark-adapted (before and after the illumination) and lightexposed leaves were measured at ambient temperature with a portable fluorometer (PAM-2000, Heinz Walz, Effeltrich, Germany) (Weng et al. 2010). All measurements were taken before 11:00 $\mathrm{h}$ to avoid the midday depression in photosynthesis. Values of the minimal ChlF $\left(\mathrm{F}_{0}\right)$ and maximal $\mathrm{ChlF}\left(\mathrm{F}_{\mathrm{m}}\right)$ of dark-adapted samples were respectively determined using modulated irradiation of a weak light-emitting diode (LED) beam (measuring light) and saturating pulse. We then calculated the maximum photochemical quantum yield $\left(\mathrm{F}_{\mathrm{v}} / \mathrm{F}_{\mathrm{m}}\right)$, where $\mathrm{F}_{\mathrm{v}}$, the yield of variable fluorescence, was calculated as $\left(\mathrm{F}_{\mathrm{m}}-\mathrm{F}_{0}\right)$. When measuring $F_{v} / F_{m}$, samples were first acclimated to dark conditions to ensure that all reaction centers were in an open state, and there was minimal nonphotochemical dissipation of excitation energy. $F_{v} / F_{m}$ is an index of the photosynthetic potential as well as the potential for photochemical dissipation, and reveals the percentage of PSII that is open and its effectiveness in capturing complexes from photoenergy and later transfer to quanta (Fracheboud and Leipner 2003). The actual PSII efficiency $\left(F_{\mathrm{v}}{ }^{\prime} / \mathrm{F}_{\mathrm{m}}{ }^{\prime}\right)$ was calculated as $\left(\mathrm{F}_{\mathrm{m}}{ }^{\prime}-\mathrm{F}_{0}{ }^{\prime}\right) / \mathrm{F}_{\mathrm{m}}{ }^{\prime} \cdot \mathrm{F}_{0}{ }^{\prime}$ and $\mathrm{F}_{\mathrm{m}}{ }^{\prime}$ are the actual and maximal levels of fluorescence during illumination, respectively; the former was determined at each PPFD level, and the latter was determined by applying a saturating flash. From these data, nonphotochemical quenching (NPQ) could be computed based on the modulated fluorescence kinetics: $N P Q=\left(F_{m}-F_{m}{ }^{\prime}\right) / F_{m}{ }^{\prime}$ (Porcar-Castell et al. 2008). Measurements were recorded with WinControl-3 software (Heinz Walz).
Statistical analysis: All measurements and analyses were performed on leaf areas with different pigmentation in three biological replicates. One plant was used for all types of analyses, and the number of plants was 16-30. All experiments were arranged in a completely randomized design. All parameters were subjected to a one-way analysis of variance $(A N O V A)$, with a significance level of $p \leq 0.05$ using CoStatstatisticalsoftware(CohortBerkeley, Monterey, CA, USA). Regression analyses were used to examine relationships among $\mathrm{Chl}(a+b)$, pigments, and Ant. In addition, model datasets were based on at least 48 leaves from each PPFD level, and ChlF parameters were calculated using $\mathrm{Chl}(a+b)$ data from the model validation datasets. Several models were tested, with the nonlinear regression model being selected as the best interpretation of the relationship between ChlF parameters and the PPFD. All models were evaluated for goodness of fit by graphical analysis of residuals, and by computing the correlation coefficient $(r)$ and determination coefficient $\left(r^{2}\right)$. Each experiment was performed twice independently with a randomized design for the growth environment, sampling day, and ChlF analyses. All graphs were created with Sigmaplot 10.0 (Systat Software, San Jose, CA, USA).

\section{Results}

Changes in spectral characteristics and $\mathrm{Chl}$ contents in different leaf colors: Leaf pigments and contents affect the leaf absorbance spectra. Leaves of C. blumei had widely varying $\mathrm{Chl}$ contents and exhibited variable leaf optical properties of transmittance and reflectance (Fig. 1). In the blue range, reflectance of leaves was high and widely varied among Chl contents in all leaves. In contrast, transmittance of all leaves converged to a narrow range of around 0.03 with a smaller variability. In the green range, the transmittance and reflectance showed higher variability in green parts of leaves compared to red parts. However, in the red range, the reflectance showed higher variability in red parts of leaves compared to green parts. Therefore, the transmittance and reflectance of green parts of leaves (Fig. 1 $A, C$ ) was strikingly higher than that of red parts (Fig. $1 B, D$ ) at $500-600-\mathrm{nm}$ wavebands. In the visible light range $(400-700 \mathrm{~nm})$, the transmittance and reflectance gradually increased with a decrease in the Chl content in green parts of leaves. In the red light range, the transmittance and reflectance gradually increased with a decrease in the Chl content in red parts of leaves. Nevertheless, the reflectance and transmittance of leaves at 690-850-nm wavebands did not show any trend between spectra and Chl content in leaf colors.

Relationships among Chl, Car, and Ant: Relationships among Chl $(a+b) v s$. SPAD, Car, Car/Chl, Ant, Chl $a$, and $\mathrm{Chl} a / b$ in green and red portions of leaves are presented in Fig. 2. Regression analyses showed that $\mathrm{Chl} a$, Car, and SPAD were significantly and positively correlated with Chl $(a+b)$ at $r=0.99-0.996,0.855-0.882$, and 0.962-0.985 in green and red parts of leaves, respectively (Fig. $2 A-C$ ), However, calibration curves of $\mathrm{Chl} a / b$ and $\mathrm{Car} / \mathrm{Chl}$ were nonlinear to $\mathrm{Chl}(a+b)$ (Fig. $2 D, E)$. In particular, the 

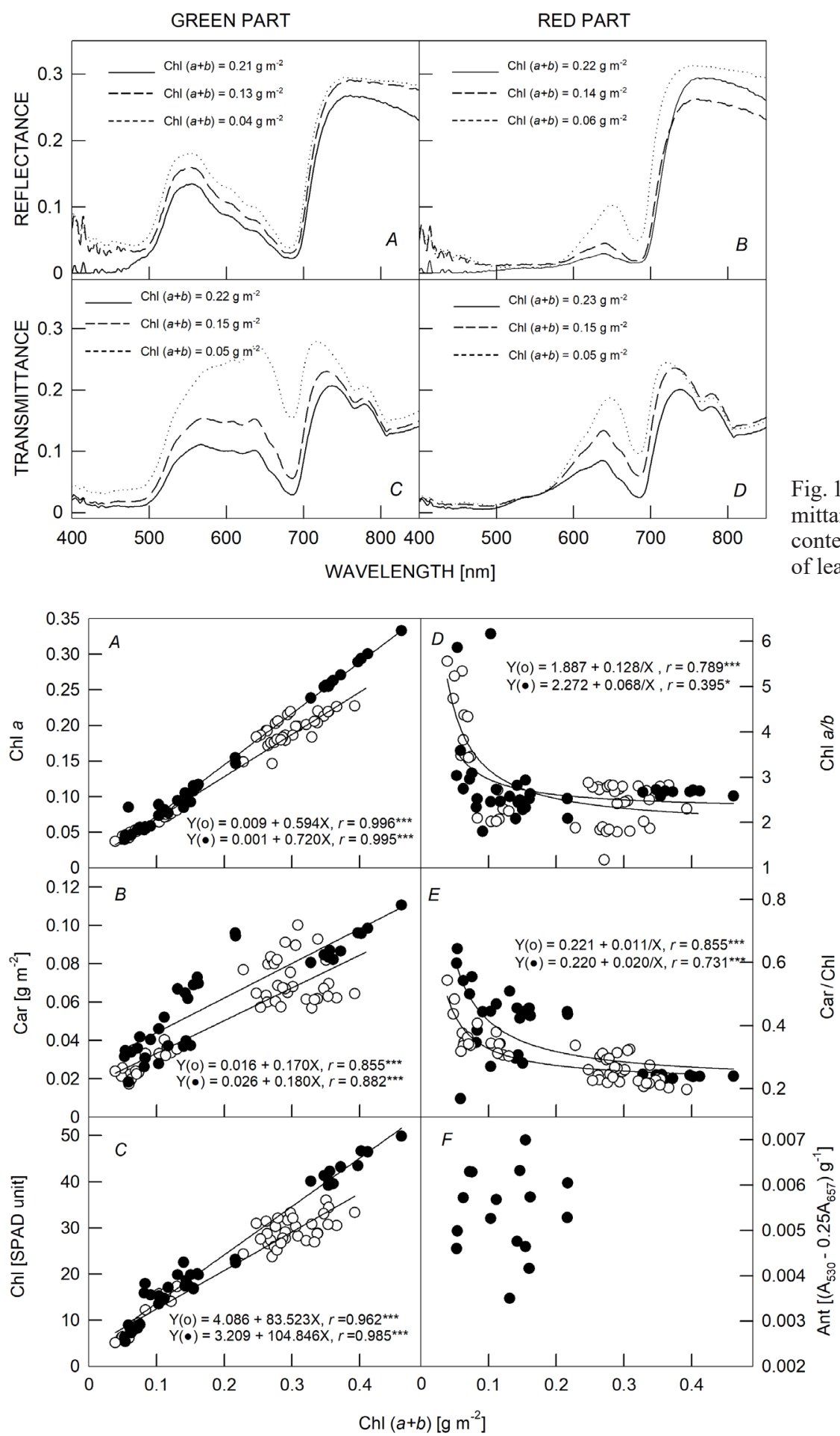

Fig. 1. Changes in the spectral reflectance and transmittance with different total Chl [i.e., Chl $(a+b)]$ contents in green sectors $(A, C)$ and red sectors $(B, D)$ of leaves of Coleus blumei plants.

Fig. 2. Relationships between Chl $(a+b)$ content and Chl $a(A)$, carotenoids (Car) $(B)$, soil-plantanalysis development(SPAD) $(C)$, Chl $a / b(D), \mathrm{Car} / \mathrm{Chl}(E)$, and anthocyanins (Ant) $(F)$ of red and green parts of leaves of Coleus blumei plants. Each symbol represents the average of one plant with three leaves, and 16-30 plants were randomly selected from each treatment. Each Chl pigment index was calculated using red (black circle) and green (white circle) leaf data $(n=48-90)$ from the model's validation datasets. The correlation coefficient $(r)$ and significance of the regression are shown $\left({ }^{*}-p<0.05 ;{ }^{* * *}-p<0.001\right)$.

relationship of Chl $(a+b)$ and $\mathrm{Chl} a / b$ in red parts of leaves was weak $(r=0.395, p<0.05)$. Ant contents in green parts of leaves were undetectable, and a no distinct relationship was observed between Ant and $\mathrm{Chl}(a+b)$ in red parts of leaves, indicating that the red parts mainly resulted from the Ant accumulation (Fig. $2 F$ ). In addition, the analysis of photosynthetic pigments showed differences in amounts of $\mathrm{Chl}$ and Car, as well as in their ratios within variegated leaves of the tested plants. Green areas had much higher ratios of $\mathrm{Chl} a / b$ and $\mathrm{Car} / \mathrm{Chl}$ than the red areas. Car contents in red and green parts of leaves did not significantly differ, and changes in the $\mathrm{Car} / \mathrm{Chl}$ ratio were therefore attributed to the total $\mathrm{Chl}$ content in the leaves.

Correlations between $\mathrm{Chl}$ contents and ChIF measurements at different leaf parts in response to PPFD treatments: Responses of $\mathrm{F}_{0}, \mathrm{~F}_{\mathrm{m}}$, and $\mathrm{F}_{\mathrm{v}} / \mathrm{F}_{\mathrm{m}}$ to $\mathrm{Chl}(a+b)$ in red and green parts of leaves of $C$. blumei plants 
under different PPFDs showed that PPFD effects on the ChlF parameter differed (Fig. $3 A, H, O)$. However, responses of $\mathrm{F}_{0}, \mathrm{~F}_{\mathrm{m}}$, and $\mathrm{F}_{\mathrm{v}}{ }^{\prime} / \mathrm{F}_{\mathrm{m}}$ ' to $\mathrm{Chl}(a+b)$ in red and green parts of leaves of $C$. blumei plants showed different ChlF parameters under different PPFDs (Fig. $3 B-G, 3 I-N$, and $3 P-U$ ). There were strongly significant correlations $(r=0.772-0.843, p<0.001)$ among Chl $(a+b)$ and $\mathrm{F}_{0}\left(\right.$ or $\left.\mathrm{F}_{0}{ }^{\prime}\right)$ in response to all PPFD levels and the dark (Fig. 3A-G). Trends of $\mathrm{F}_{\mathrm{m}}$ (or $\mathrm{F}_{\mathrm{m}}{ }^{\prime}$ ) against $\mathrm{Chl}(a+b)$ in both red and green parts of leaves were similar to those of $\mathrm{F}_{0}\left(\right.$ or $\left.\mathrm{F}_{0}{ }^{\prime}\right)$ in response to PPFD (Fig. $3 H-N$ ). A high PPFD-induced decreases in $\mathrm{F}_{\mathrm{m}}$ ', and the value of
$\mathrm{F}_{\mathrm{m}}$ (or $\mathrm{F}_{\mathrm{m}}{ }^{\prime}$ ) was found to remain in a narrow range in both green and red parts of leaves. Compared to low PPFDs

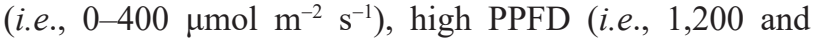
$2,000 \mu \mathrm{mol} \mathrm{m} \mathrm{m}^{-2} \mathrm{~s}^{-1}$ ) yielded relatively lower values of $\mathrm{F}_{\mathrm{m}}{ }^{\prime}$ from 10 to 50 readings of $\mathrm{Chl}(a+b)$. Nevertheless, $\mathrm{F}_{\mathrm{v}}{ }^{\prime} / \mathrm{F}_{\mathrm{m}}{ }^{\prime}$ was neither strongly correlated with $\mathrm{Chl}(a+b)$ at PPFD of 200 and $400 \mu \mathrm{mol} \mathrm{m} \mathrm{m}^{-2} \mathrm{~s}^{-1}(r=0.457-0.561, p<0.05$ and 0.01 , respectively; Fig. $3 P, Q)$, nor correlated with Chl $(a+b)$ at PPFD of 0,$800 ; 1,200$; and $2,000 \mu \mathrm{mol} \mathrm{m}^{-2} \mathrm{~s}^{-1}$ and the dark (Fig. 3O,R-U). In general, $\mathrm{F}_{\mathrm{v}} / \mathrm{F}_{\mathrm{m}}$ in darkadapted red parts of leaves was higher than that of green parts of leaves (Fig. 3U). Moreover, under different PPFD
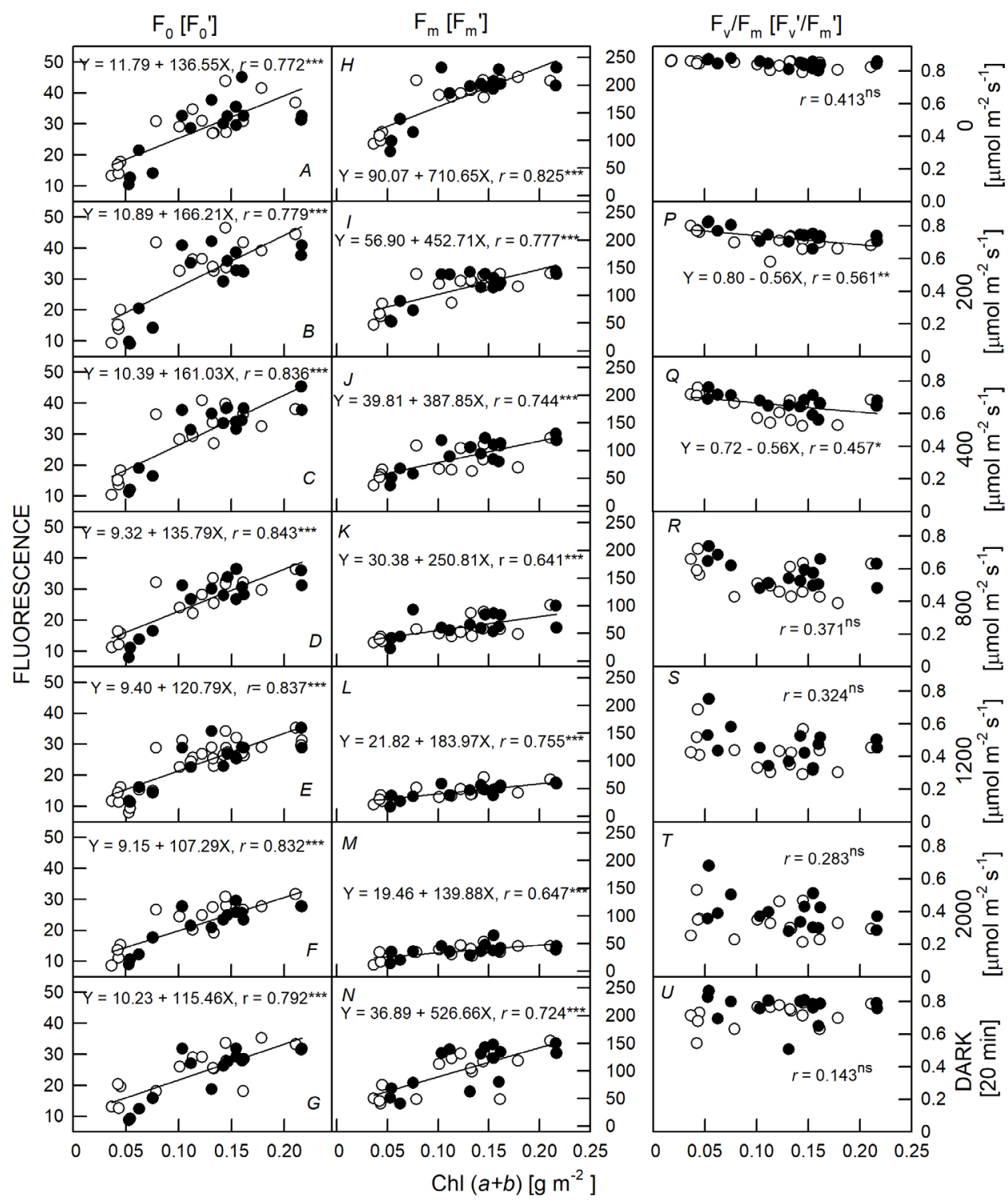

Fig. 3. Relationships between $\mathrm{Chl}(a+b)$ concentrations and $\mathrm{Chl}$ fluorescence $(\mathrm{ChlF})$ parameters of the minimum fluorescence yield in a dark-adapted state $\left(\mathrm{F}_{0}\right)(A)$, the actual level of fluorescence during illumination $\left(\mathrm{F}_{0}{ }^{\prime}\right)(B-G)$, maximum fluorescence yield in a dark-adapted state $\left(\mathrm{F}_{\mathrm{m}}\right)(H)$, the maximal level of fluorescence during illumination $\left(\mathrm{F}_{\mathrm{m}}{ }^{\prime}\right)(I-N)$, the maximum photochemical quantum yield $\left(\mathrm{F}_{\mathrm{v}} / \mathrm{F}_{\mathrm{m}}\right)(O)$, and the actual PSII efficiency $\left(\mathrm{F}_{\mathrm{v}}{ }^{\prime} / \mathrm{F}_{\mathrm{m}}{ }^{\prime}\right)(P-U)$ of red and green parts of leaves of Coleus blumei plants with respect to different light intensity treatments (PPFD of $0,200,400,800 ; 1,200$; and 2,000 $\mu \mathrm{mol} \mathrm{m}^{-2} \mathrm{~s}^{-1}$ ) for $20 \mathrm{~min}$, and dark conditions (20 min). Each symbol represents the average of one plant with three leaves, and 16 plants were randomly selected from each treatment. Each Chl pigment index was calculated using red (black circle) and green (white circle) leaf data $(n=48)$ from the model's validation datasets. The correlation coefficient $(r)$ and significance of the regression are shown $\left({ }^{*}-p<0.05 ;{ }^{* *}-p<0.01 ;{ }^{* * *}-p<0.001\right.$; ns - insignificant). 
treatments, the $\mathrm{F}_{\mathrm{v}}{ }^{\prime} / \mathrm{F}_{\mathrm{m}}{ }^{\prime}$ values of leaves with different $\mathrm{Chl}$ contents were similar.

The relationship between the PPFD and $\mathrm{F}_{0}{ }^{\prime}$ slope showed no detectable difference in any leaves (Fig. 4A). Nevertheless, the regression analysis showed that the $\mathrm{F}_{0}{ }^{\prime}$ intercept and $\mathrm{F}_{\mathrm{m}}{ }^{\prime}$ slope and intercept were significantly correlated with PPFD, with $r=0.986,0.996$, and $0.993(p<0.001)$, respectively, and a significant decrease in the PPFD level was also observed for the $\mathrm{F}_{0}{ }^{\prime}$ intercept and $\mathrm{F}_{\mathrm{m}}{ }^{\prime}$ slope and intercept (Fig. 4B-D). PPFD variations in response to NPQ at red and green parts of leaves are demonstrated in Fig. 5. Insignificant correlations were detected between NPQ and Chl $(a+b)$ at all PPFD treatments. NPQ values of leaves with the higher $\mathrm{Chl}$ contents were almost the same as those of leaves with lower $\mathrm{Chl}$ contents in response to different PPFD treatments. High PPFD (Fig. $5 E$ ) resulted in higher NPQ compared to low PPFD (Fig. $5 A, B$ ). invasive pigment estimation models.

Fig. 2 illustrated that red and green leaf sectors of C. blumei plants had wide variations in pigment contents, clearly suggesting that SPAD can be used as more precise metrics for developing leaf $\mathrm{Chl}$ estimation algorithms due to high correlations. In addition, the high SPAD of leaves indicated that more leaves had higher Chl concentrations. In our study, the Chl $a / b$ ratio in the red parts of leaves was lower than that of green parts, suggesting that it could be an indicator for estimating relative photosystem stoichiometry (Pfannschmidt et al. 1999). Plants grown under controlled ozone treatments appeared to synthesize more $\mathrm{Chl} a$ because it has a wider spectrum compared to that of $\mathrm{Chl} b$, and Chl $a$ is the molecule that makes photosynthesis possible (Calatayud et al. 2004). Furthermore, a change in the Chl $a / b$ ratio is usually positively correlated with variations in PSII light-harvesting antenna size (Leong and Anderson

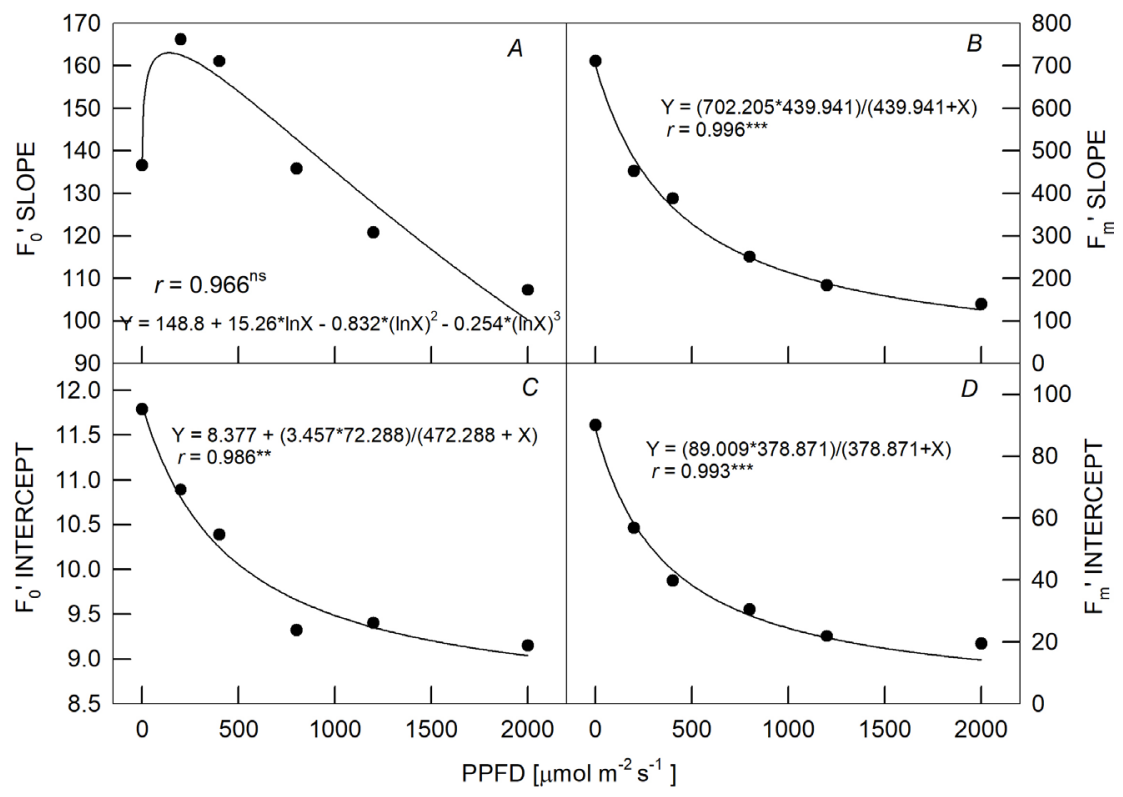

Fig. 4. Photosynthetic photon flux density (PPFD) treatment $(0,200,400,800 ; 1,200$; and $2,000 \mu \mathrm{mol} \mathrm{m} \mathrm{m}^{-2} \mathrm{~s}^{-1}$ ) for $20 \mathrm{~min}$ in response to changes in minimum fluorescence yield in a light-adapted state $\left(\mathrm{F}_{0}{ }^{\prime}\right)$ slope $(A)$, maximum fluorescence yield in a lightadapted state $\left(\mathrm{F}_{\mathrm{m}}{ }^{\prime}\right)$ slope $(B), \mathrm{F}_{0}$ intercept $(C)$, and $\mathrm{F}_{\mathrm{m}}$ ' intercept $(D)$ from all leaves of tested plants. The correlation coefficient $(r)$ and significance of the regression curve are shown $\left({ }^{* *}-p<0.01{ }^{* * *}-p<0.001\right.$; ns insignificant).

\section{Discussion}

The reflectance and transmittance of green leaves was different from that of red leaves at 400-700 nm (Fig. 1), and the reflectance and transmittance decreased when both $\mathrm{Chl}$ and Car contents were enhanced in green leaves (Fig. 2B). In red leaves, the reflectance and transmittance of $550 \mathrm{~nm}$ was much lower compared to the green leaves, but it peaked around $650 \mathrm{~nm}$, suggesting that the light absorbance of Ant in red leaves resulted in the lower reflectance and transmittance at $550 \mathrm{~nm}$ (Merzlyak et al. 2003, Gitelson and Merzlyak 2004). Although changes in variegated leaf colors are complex, the light absorbance increased with the enhanced Chl content, especially in green portions of leaves. However, the light absorbance of multicolored leaves was not affected by the increasing Chl content at 690-850 nm (Carter and Young 1993). This study provides deeper insights into the interception of light by photosynthetic and photoprotective pigments as a function of light intensity conditions, which is important for plant biology as well as knowledge-driven selection of spectral bands for non-
1984). In our study, SPAD measurements were performed at 650 and $940 \mathrm{~nm}$, i.e., at wavelengths not absorbed by Ant, whose peak absorbance is at 500-550 nm (Landi et al. 2015). Moreover, no correlation of Ant with $\mathrm{Chl}(a+b)$ in red parts of leaves was observed. This was because the color of all adaxial parts was red, and content of Ant in red leaf was not affected by the Chl content.

Measuring the yield of ChlF gives specific information about the photochemical efficiency and heat dissipation. ChlF components can be used to measure different functional levels of photosynthesis, and changes in ChlF can be also used to quickly assess plant physiological responses during stress (Laing et al. 2000). $\mathrm{F}_{\mathrm{v}} / \mathrm{F}_{\mathrm{m}}$ (or $\mathrm{F}_{\mathrm{v}}{ }^{\prime} / \mathrm{F}_{\mathrm{m}}{ }^{\prime}$ ) shows the actual photochemical ability of PSII under light conditions and has a linear relationship with the $\mathrm{CO}_{2}$ fixation rate (Cui et al. 2006). Studies of the effects of light intensities on ChlF components of $C$. blumei plants in regard to their ability of photosynthetic activity are scarce. $F_{0}$ (or $\mathrm{F}_{0}{ }^{\prime}$ ) and $\mathrm{F}_{\mathrm{m}}\left(\right.$ or $\left.\mathrm{F}_{\mathrm{m}}{ }^{\prime}\right)$ indices showed gradual increases as Chl $(a+b)$ increased at different PPFDs. Significant correlations were observed between PPFD and the $\mathrm{F}_{0}$ intercept 


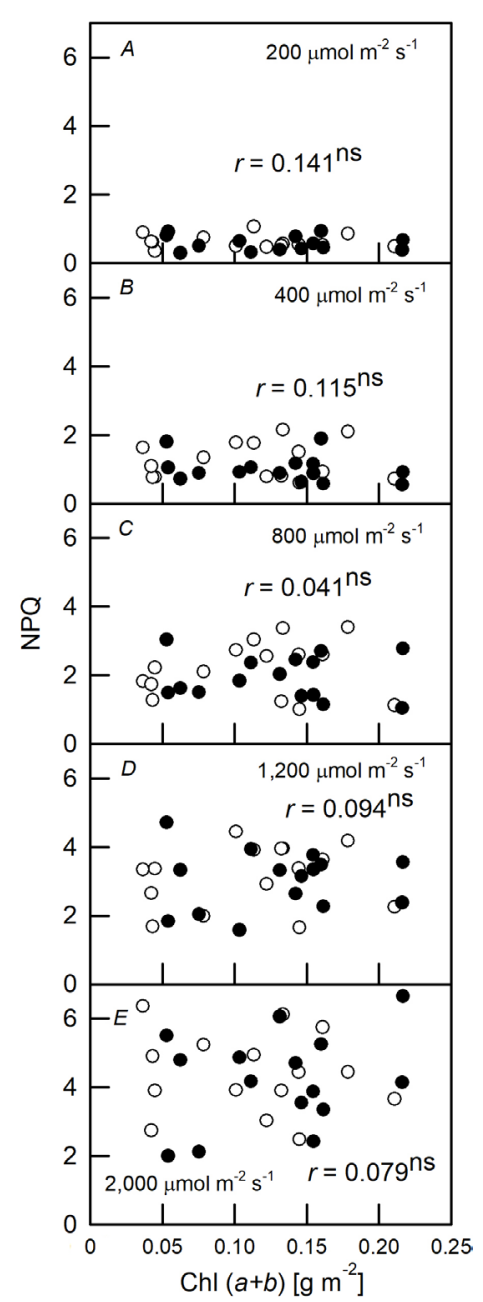

Fig. 5. The correlation coefficient between $\mathrm{Chl}(a+b)$ concentrations and the nonphotochemical quenching (NPQ) index was calculated under PPFD treatments of $200(A), 400(B), 800(C)$; $1,200(D)$; and 2,000 $(E) \mu \mathrm{mol} \mathrm{m}^{-2} \mathrm{~s}^{1}$ for $20 \mathrm{~min}$.

and between the $\mathrm{F}_{\mathrm{m}}$ slope and intercept in C. blumei plants. Consequently, $\mathrm{F}_{0}$ and $\mathrm{F}_{\mathrm{m}}$ are more comprehensively applicable to nondestructive estimates of Chl contents of plant leaves. $\mathrm{F}_{0}$ and $\mathrm{F}_{\mathrm{m}}$ indices respond to slight changes in $\mathrm{Chl}$ and also give accurate estimates of changes in the photosynthetic flux of $C$. blumei canopies, since $\mathrm{Chl}$ pigments are closely related to PSII photochemical efficiency and dissipation of light energy not used in photosynthesis (Frank et al. 1994, Gitelson and Merzlyak 1994, Björkman and Demmig-Adams 1995). The different colors of leaves exhibit their abilities and specificities of ChlF in response to PPFD. As a result, different leaf colors show different responses, and they can be used as a PPFD-plant model to investigate pigment composition under PPFD exposure. Moreover, red and green parts of leaves of C. blumei plants developed at a given PPFD could be separated on the basis of $\mathrm{F}_{0}$ and $\mathrm{F}_{\mathrm{m}}$ at a given light intensity, indicating that ChlF can monitor PS efficiency of red and green leaves under various PPDFs.

In our study, $\mathrm{Chl}(a+b)$ was positively and significantly correlated to $\mathrm{F}_{0}^{\prime}$ (Fig. $3 G$ ) and $\mathrm{F}_{\mathrm{m}}{ }^{\prime}$ (Fig. $3 N$ ) of red and green leaves under dark conditions for $20 \mathrm{~min}$. However, insignificant difference was found between $\mathrm{Chl}(a+b)$ and $\mathrm{F}_{\mathrm{v}}{ }^{\prime} / \mathrm{F}_{\mathrm{m}}{ }^{\prime}$ (Fig. 3U) of red and green leaves in response to dark for $20 \mathrm{~min}$. The slope of $\mathrm{F}_{0}\left(\mathrm{~F}_{0}^{\prime}\right)$ against $\mathrm{Chl}(a+b)$ in both red and green leaves was between 166.21-107.29 (Fig. $3 A-F$ ) which did not change too much as PPFD increased. Nevertheless, the slope of $\mathrm{F}_{\mathrm{m}}\left(\mathrm{F}_{\mathrm{m}}{ }^{\prime}\right)$ against Chl $(a+b)$ in both parts of leaves declined from 710.67 to 139.88 as PPFD increased (Fig. $3 H-M$ ), indicating that $\mathrm{F}_{\mathrm{m}}{ }^{\prime}$ was less affected by $\mathrm{Chl}(a+b)$ content under high PPFDs (i.e., 800-2,000 $\left.\mu \mathrm{mol} \mathrm{m} \mathrm{m}^{-2} \mathrm{~s}^{-1}\right)$. Furthermore, exposure to high PPFDs might have caused decreases in $\mathrm{F}_{\mathrm{v}}{ }^{\prime} / \mathrm{F}_{\mathrm{m}}{ }^{\prime}$ values of both green and red parts of leaves in C. blumei plants. All plants showed low $\mathrm{F}_{\mathrm{v}}{ }^{\prime} / \mathrm{F}_{\mathrm{m}}{ }^{\prime}$ of $0.2-0.7$ with high PPFDs. Exposure of plant leaves to illumination that exceeds their photosynthetic capacity leads to photoinhibition of the electron transport system. The susceptibility of photosynthesis to photoinhibition strongly depends on growth light intensities to which the plant is exposed. The excess energy in PSII increases, leading to increase of $F_{0}$ and decrease of $F_{m}$ values due to greater photoinhibition when plants are exposed to higher PPFDs. Lower $\mathrm{F}_{\mathrm{v}}{ }^{\prime} / \mathrm{F}_{\mathrm{m}}{ }^{\prime}$ values might be obtained in a plant at higher PPFDs. Experiencing higher PPFDs destabilizes the PSII, resulting in a separation between LHCII and PSII reaction centers that increase $\mathrm{F}_{0}$ and $\mathrm{F}_{\mathrm{m}}$ at different rates (Makarenko et al. 2016).

Although $\mathrm{F}_{0}, \mathrm{~F}_{\mathrm{m}}, \mathrm{F}_{\mathrm{v}} / \mathrm{F}_{\mathrm{m}}$, and NPQ were related through photochemical quenching, $F_{\mathrm{v}} / \mathrm{F}_{\mathrm{m}}$ and NPQ were less sensitive to $\mathrm{Chl}(a+b)$ than were $\mathrm{F}_{0}$ and $\mathrm{F}_{\mathrm{m}}$ in response to PPFD. Under different PPFD treatments, $\mathrm{F}_{\mathrm{v}} / \mathrm{F}_{\mathrm{m}}\left(\mathrm{F}_{\mathrm{v}}{ }^{\prime} / \mathrm{F}_{\mathrm{m}}{ }^{\prime}\right)$ and NPQ of leaves of $C$. blumei with higher Chl contents were almost the same as those of leaves with lower Chl contents, suggesting that under visible light illumination, both green and red parts of leaves with lower Chl contents avoid excessive energy absorption through higher reflectance and transmittance, and respond to higher PSII photochemical efficiencies with the higher Chl content. Responses of $\mathrm{F}_{\mathrm{v}} / \mathrm{F}_{\mathrm{m}}\left(\mathrm{F}_{\mathrm{v}}{ }^{\prime} / \mathrm{F}_{\mathrm{m}}{ }^{\prime}\right)$ and NPQ to light intensities indicated that the tested plants appeared to be adapted to low-light intensities or were sensitive to high-light intensity conditions, and often suffered serious photoinhibition and photodamage. Protective mechanisms in C. blumei plants should prevent leaves from excessive reduction of PSII aceptors in plants.

No significant relationships between NPQ and Chl contents of the tested plant leaves were observed, suggesting that thermal energy dissipation did not take place in antennae.

The PPFD influences the photosynthetic potential of $C$. blumei plants and different responses to $\mathrm{Chl}(a+b)$ contents in red and green parts of leaves depend on the red and green parts of the leaves. ChlF parameters were PPFDspecific and were not expressed solely in response to increasing excess light energy. In order to characterize the photosynthetic capacity of plants, the light-response curve and the consequent base points produce very important parameters. However, steady-state conditions, which are strictly required, do not occur in nature. So, instantaneous light-response curves, with quick alterations in the PPFD but with a clear risk of encountering non-steady-state 
conditions, can be used as an alternative way to achieve insights into light-response characteristics of plants in the field. Our findings suggest that $\mathrm{F}_{0}$ and $\mathrm{F}_{\mathrm{m}}$ were strongly correlated with $\mathrm{Chl}$ contents in response to PPFD, and may be used as criteria for differentiating between plants tolerant to high light intensities, and can provide a quantitative assessment for the early screening of high PPFDtolerant $C$. blumei plants to overcome high light intensity stress. In addition, $F_{m}$ and $F_{v} / F_{m}$ indices can be used as indicators to characterize the physiology of $C$. blumei plants in response to PPFD. In short, these higher ChlF values under high PPFDs can be used to select for the maintenance of photosynthetic capacity with high PPFDs by plant breeding. For instance, the average time required to measure $\mathrm{F}_{0}$ from a pre-dark-adapted sample is only $1 \mathrm{~s}$. This means that many hundreds of individual plants can be screened per day, providing ample opportunity for the discovery of individuals that manifest quality indicators and exhibit greater seedling quality. Not only can simple evaluations of photosynthesis be made, but the relationships among photosynthetic efficiency, heat dissipation, and fluorescence can also be assessed. Improved high-PPFD tolerance of the photosynthetic apparatus of C. blumei plants may, therefore, substantially contribute to improving the performance of the crop in light-intense regions by increasing early vigor and extending the culture period.

We observed that a large number of variegated leaves exist during florescence, but after florescence, the variegated leaves do not occur on new branches. The photosynthetic function of variegated leaves was retained in the early stages of leaf development. More important is that the number of flowers significantly decreased when girdling occurred between variegated leaves and flowers. Therefore, in practice, maintaining or strengthening the photosynthetic capacity of red and green parts of leaves during variegated leaf development may be of great significance for $C$. blumei flowering. Therefore, in field cultivation, choosing a suitable region or using artificial shading should be considered in order to avoid photoinhibition resulting from high-light intensity exposure. More opportunities exist for modifying Chl contents including broader interest features (e.g., branch and/ or node numbers) to floriculture crop producers or to emphasize important traits.

In conclusion, ChlF components were used to measure indirectly the different functional levels of photosynthesis. We showed that different colors of leaves displayed variations in their photosynthetic apparatus associated with $\mathrm{Chl}$ contents in a PPFD response. Upon exposure to high PPFDs, $F_{m}{ }^{\prime}$ and $F_{v}{ }^{\prime} / F_{m}{ }^{\prime}$ of $C h l$ contents in leaves were strongly lowered. In addition, both $\mathrm{F}_{0}$ and $\mathrm{F}_{\mathrm{m}}$ can be used to assess Chl contents due to their high correlations, and can prove to be useful in further physiological studies on C. blumei plants with high PPFD tolerance. These data reflect the morphological and physiological attributes that contribute to our perception of crop quality and subsequent growth in outdoor planting sites.

\section{References}

Adams W.W., Zarter C.R., Ebbert V., Demmig-Adams B.: Photo- protective strategies of overwintering evergreens. - BioScience 54: 41-49, 2004.

Aleric K.M., Kirkman L.K.: Growth and photosynthetic responses of the federally endangered shrub, Lindera melissifolia (Lauraceae), to varied light environment. - Am. J. Bot. 92: 682-689, 2005.

Anderson J.M., Park Y.I., Chow W.S.: Photoinactivation and photoprotection of photosystem II in nature. - Physiol. Plantarum 100: 214-223, 1997.

Björkman O., Demmig-Adams B.: Regulation of photosynthetic light energy capture, conversion, and dissipation in leaves of higher plants. - In: Schulze E.D., Caldwell M.M. (ed.): Ecophysiology of Photosynthesis. Pp. 17-47. Springer, Berlin 1995.

Bonneville M.C., Fyles J.W.: Assessing variations in SPAD-502 chlorophyll meter measurements and their relationships with nutrient content of trembling aspen foliage. - Com. Soil Sci. Plant Anal. 37: 525-539, 2006.

Borek M., Bączek-Kwinta R., Rapacz M.: Photosynthetic activity of variegated leaves of Coleus $\times$ hybridus hort. cultivars characterised by chlorophyll fluorescence techniques. - Photosynthetica 54: 331-339, 2016.

Calatayud A., Barreno E.: Response to ozone in two lettuce varieties on chlorophyll $a$ fluorescence, photosynthetic pigments and lipid peroxidation. - Plant Physiol. Bioch. 42: 549-555, 2004.

Carter G.A., Young D.R.: Foliar spectral reflectance and plant stress on a barrier island. - Int. J. Plant Sci. 154: 298-305, 1993.

Cui L., Li J., Fan Y. et al.: High temperature effects on photosynthesis, PSII functionality and antioxidant activity of two Festuca arundinacea cultivars with different heat susceptibility. - Bot. Stud. 47: 61-69, 2006.

de la Rosa-Manzano E., Andrade J.L., García-Mendoza E. et al.: Photoprotection related to xanthophyll cycle pigments in epiphytic orchids acclimated at different light microenvironments in two tropical dry forests of the Yucatan Peninsula, Mexico. - Planta 42: 1425-1438, 2015.

Demmig-Adams B., Adams W.W., Barker D.H. et al.: Using chlorophyll fluorescence to assess the fraction of absorbed light allocated to thermal dissipation of excess excitation. Physiol. Plantarum 98: 253-264, 1996.

Dewir Y.H., El-Mahrouk M.E.S., Al-Shmgani H.S. et al: Photosynthetic and biochemical characterization of in vitroderived African violet (Saintpaulia ionantha $\mathrm{H}$. Wendl) plants to ex vitro conditions. - J. Plant Interact. 10: 101-108, 2015.

Dos Anjos L., Oliva M.A., Kuki K.N.: Fluorescence imaging of light acclimation of Brazilian Atlantic forest tree species. Photosynthetica 50: 95-108, 2012.

Fracheboud Y., Leipner J.: The application of chlorophyll fluorescence to study light, temperature, and drought stress. Plant Biol. 51: 125-150, 2003.

Frank H.A., Cua A., Chynwat V. et al.: Photophysics of the carotenoids associated with the xanthophyll cycle in photosynthesis. - Photosynth. Res. 41: 389-395, 1994.

Gitelson A., Merzlyak M.N.: Spectral reflectance changes associated with autumn senescence of Aesculus hippocastanum L. and Acer platanoides L. leaves. Spectral features and relation to chlorophyll estimation. - J. Plant Physiol. 143: 286-292, 1994.

Gitelson A.A., Merzlyak M.N.: Non-destructive assessment of chlorophyll, carotenoid and anthocyanin content in higher plant leaves: Principles and algorithms. - In: Stamatiadis S., Lynch J.M., Schepers J.S. (ed.): Remote Sensing for Agriculture and the Environment. Pp. 78-94. Peripheral Publications Ella, Larissa 2004. 
Huang C., Zhao S., Wang L. et al.: Alteration in chlorophyll fluorescence, lipid peroxidation and antioxidant enzymes activities in hybrid ramie (Boehmeria nivea L.) under drought stress. - Austr. J. Crop Sci. 7: 594-599, 2013.

Konoplyova A., Petropoulou Y., Yiotis C. et al.: The fine structure and photosynthetic cost of structural leaf variegation. Flora 203: 653-662, 2008.

Laing W., Greer D., Sun O. et al.: Physiological impacts of magnesium $(\mathrm{Mg})$ deficiency in Pinus radiata: Growth and photosynthesis. - New Phytol. 146: 47-57, 2000.

Landi M., Tattini M., Gould K.S.: Multiple functional roles of anthocyanins in plant-environment interactions. - Environ. Exp. Bot. 119: 4-17, 2015.

Leong T.Y., Anderson J.M.: Adaptation of the thylakoid membranes of pea chloroplasts to light intensities. I. Study on the distribution of chlorophyll-protein complexes. - Photosynth. Res. 5: 105-115, 1984.

Liakopoulos G., Spanorigas I.: Foliar anthocyanins in Pelargonium $\times$ hortorum are unable to alleviate light stress under photoinhibitory conditions. - Photosynthetica 50: 254-262, 2012.

Lichtenthaler H.K.: Chlorophylls and carotenoids, the pigments of photosynthetic biomembranes. - Method. Enzymol. 148: 350-382, 1987.

Makarenko M.S., Kozel N.V., Usatov A.V. et al.: A state of PSI and PSII photochemistry of sunflower yellow-green plastome mutant. - Online J. Biol Sci. 16: 193-198, 2016.

Mancinelli A.L., Rabino I.: Photoregulation of anthocyanin synthesis. X. Dependence of photosynthesis of high irradiance response anthocyanin synthesis in Brassica oleracea leaf disks and Spirodela polyrrhiza. - Plant Cell Physiol. 25: 1153-1160, 1984.

Merzlyak M.N., Solovchenko A.E., Gitelson A.A.: Reflectance spectral features and non-destructive estimation of chlorophyll, carotenoid and anthocyanin content in apple fruit. Postharvest Biol. Tec. 27: 197-211, 2003.

Molina-Bravo R., Arellano C., Sosinski B.R., Fernandez G.E.: A protocol to assess heat tolerance in a segregating population of raspberry using chlorophyll fluorescence. - Sci. Hortic.Amsterdam 130: 524-530, 2011.

Montgomery R.A., Givnish T.J.: Adaptive radiation of photosynthetic physiology in the Hawaiian lobeliads: Dynamic photosynthetic responses. - Oecologia 155: 455-467, 2008.

Muniz C.R., Freire F.C.O., Viana F.M.P. et al.: Monitoring cashew seedlings during interactions with the fungus Lasiodiplodia theobromae using chlorophyll fluorescence imaging. Photosynthetica 52: 529-537, 2014.

Nedbal L., Soukupová J., Whitmarsh J., Trtílek M.: Postharvest imaging of chlorophyll fluorescence from lemons can be used to predict fruit quality. - Photosynthetica 38: 571-579, 2000.

Osman A.R.: Genetic variability and total phenolic compounds among six Coleus blumei varieties using RAPD analysis. J. Appl. Sci. Res. 9: 1395-1400, 2013.

Padri M., Umponstira C.: Physiological and morphological responses to ozone exposure of coleus (Solenostemon scutellarioides (L.) Codd) - IJASEIT 7: 2131-2138, 2017.

Pfannschmidt T., Nilsson A., Allen J.F.: Photosynthetic control of chloroplast gene expression. - Nature 397: 625-628, 1999.

Pineda M., Soukupová J., Matouš K. et al.: Conventional and combinatorial chlorophyll fluorescence imaging of tobamovirus-infected plants. - Photosynthetica 46: 441-451, 2008

Porcar-Castell A., Pfündel E., Korhonen J.F., Juurola E.: A new monitoring PAM fluorometer (MONI-PAM) to study the short- and long-term acclimation of photosystem II in field conditions. - Photosynth. Res. 96: 173-179, 2008.

Powles S.B.: Photoinhibition of photosynthesis induced by visible light. - Ann. Rev. Plant Physio. 35: 15-44, 1984.

Rahbarian R., Khavari-Nejad R., Ganjeali A.: Drought stress effects on photosynthesis, chlorophyll fluorescence and water relations in tolerant and susceptible chickpea (Cicer arietinum L.) genotypes. - Acta Biol. Cracov. Bot. 53: 47-56, 2011.

Takayama K., Nishina H., Iyoki S. et al.: Early detection of drought stress in tomato plants with chlorophyll fluorescence imaging - practical application of the speaking plant approach in a greenhouse. IFAC Proceedings. Vol. 44. Pp. 1785-1790, 2011.

Tanaka Y., Sasaki N., Ohmiya A.: Biosynthesis of plant pigments: anthocyanins, betalains and carotenoids. - Plant J. 54: 733-749, 2008.

Weng J.H., Jhaung L.H., Lin R.J., Chen H.Y.: Relationship between photochemical efficiency of photosystem II and the photochemical reflectance index of mango tree: Merging data from different illuminations, seasons and leaf colors. - Tree Physiol. 30: 469-478, 2010.

Wilson B., Jacobs D.F.: Chlorophyll fluorescence of stem cambial tissue reflects dormancy development in Juglans nigra seedlings. - New For. 43: 771-778, 2012.

Xue Z., Gao H., Zhao S.: Effects of cadmium on the photosynthetic activity in mature and young leaves of soybean plants. Environ. Sci. Pollut. R. 21: 4656-4664, 2014.

(C) The authors. This is an open access article distributed under the terms of the Creative Commons BY-NC-ND Licence. 